\title{
NICE to HELP: Operationalizing National Institute for Health and Clinical Excellence Guidelines to Improve Clinical Practice
}

\section{Citation}

Yue, Jirong, Patricia Tabloski, Sarah L. Dowal, Margaret R. Puelle, Rakesh Nandan, and Sharon K. Inouye. 2014. "NICE to HELP: Operationalizing National Institute for Health and Clinical Excellence Guidelines to Improve Clinical Practice." J Am Geriatr Soc 62 (4) (April): 754-761. doi:10.1111/jgs.12768.

\section{Published Version}

doi:10.1111/jgs.12768

\section{Permanent link}

http://nrs.harvard.edu/urn-3:HUL.InstRepos:32605860

\section{Terms of Use}

This article was downloaded from Harvard University's DASH repository, and is made available under the terms and conditions applicable to Other Posted Material, as set forth at http:// nrs.harvard.edu/urn-3:HUL.InstRepos:dash.current.terms-of-use\#LAA

\section{Share Your Story}

The Harvard community has made this article openly available.

Please share how this access benefits you. Submit a story.

Accessibility 


\title{
The National Institute for Health and Clinical Excellence (NICE) to Hospital Elder Life Program (HELP): Operationalizing Nice Guidelines to Improve Clinical Practice
}

\author{
Jirong Yue, M.D. ", , Patricia Tabloski, PhD, GNP-BC ${ }^{\dagger, a}$, Sarah L. Dowal, MSW, MPH ${ }^{\ddagger}$, \\ Margaret R. Puelle ${ }^{\ddagger}$, Rakesh Nandan, MBBS ${ }^{\ddagger}$, and Sharon K. Inouye, M.D., MPH ${ }^{\ddagger}, \S$ \\ *Department of Geriatrics, West China Hospital, Sichuan University, Chengdu, Sichuan Province, \\ China \\ tWilliam F Connell School of Nursing, Boston College, Boston, MA \\ ¥Aging Brain Center, Institute for Aging Research, Hebrew SeniorLife, Boston, MA \\ §Department of Medicine, Beth Israel Deaconess Medical Center, Harvard Medical School, \\ Boston, MA
}

\begin{abstract}
The National Institute for Health and Clinical Excellence (NICE) in the United Kingdom developed guidelines for the diagnosis, prevention, and management of delirium in July, 2010, which included 10 recommendations for delirium prevention. The Hospital Elder Life Program (HELP) is a targeted multicomponent strategy which has proven effective and cost-effective to prevent functional and cognitive decline in hospitalized older persons. HELP provided much of the basis for 7/10 (70\%) of the NICE recommendations. Given interest by new HELP sites to meet NICE guidelines, we developed 3 new protocols which were not previously included in the HELP program, addressing hypoxia, infection, and pain. Additionally, the NICE dehydration guideline included constipation, which was not specifically addressed in the HELP protocols. This project
\end{abstract}

(C) 1999, Hospital Elder Life Program, LLC

Address correspondence to: Sharon K. Inouye, M.D., MPH; Aging Brain Center; Hebrew SeniorLife; 1200 Centre Street; Boston, MA 02131; Phone (617) 971-5390; Fax (617) 971-5309; AgingBrainCenter@ hsl.harvard.edu.

ajirong Yue and Patricia Tabloski contributed equally to this article as co-first authors

Conflict of Interest: The editor in chief has reviewed the conflict of interest checklist provided by the authors and has determined that the authors have no financial or any other kind of personal conflicts with this paper.

This work is dedicated to the memory of Joshua Bryan Inouye Helfand.

Author Contributions: Jirong Yue: Study concept and design; acquisition of data; analysis and interpretation of data; drafting the article; critical revision of article for important intellectual content; final approval of version to be published.

Patricia Tabloski: Study concept and design; acquisition of data; analysis and interpretation of data; drafting the article; critical revision of article for important intellectual content; final approval of version to be published.

Sarah L. Dowal: Study concept and design; acquisition of data; critical revision of article for important intellectual content; final approval of version to be published.

Margaret R. Puelle: Study concept and design; acquisition of data; analysis and interpretation of data; critical revision of article for important intellectual content; final approval of version to be published.

Rakesh Nandan: Study concept and design; acquisition of data; analysis and interpretation of data; critical revision of article for important intellectual content; final approval of version to be published

Sharon K. Inouye: Study concept and design; acquisition of data; analysis and interpretation of data; drafting the article; critical revision of article for important intellectual content; final approval of version to be published; obtaining funding

Sponsor's Role: No role in the design, methods, subject recruitment, data collections, analysis and preparation of paper. 
describes the systematic development of 3 new protocols (hypoxia, infection, and pain) and the expansion of an existing HELP protocol (constipation/dehydration) to achieve alignment between the HELP protocols and NICE guidelines. Following the Institute of Medicine recommendations for developing trustworthy guidelines, we undertook a systematic review of current literature by an interdisciplinary group of experts, rated the quality of the evidence, developed intervention protocols based on the highest quality evidence, and submitted the protocols first to internal review, then external review by an interdisciplinary panel of experts. The protocols were revised based on the review process, and were incorporated into the HELP materials. Inclusion of these protocols enhances the scope of the HELP program, and allows fulfillment of NICE guideline recommendations for delirium prevention. The rigorous process we applied may provide a useful example for updating existing guidelines or protocols, which may be applicable to a broad range of clinical applications.

\section{Keywords}

Hospital Elder Life Program; NICE guidelines; delirium; prevention; hospital care

\section{Introduction}

The Hospital Elder Life Program (HELP, http://www.hospitalelderlifeprogram.org) was developed in 1993 as a targeted multicomponent strategy to prevent functional and cognitive decline in hospitalized older persons. ${ }^{1,2}$ The HELP program is an innovative model of care designed to integrate with hospital nursing staff to ensure that older patients remain as independent as possible throughout hospitalization. To date, the program has been implemented in over 200 hospitals worldwide.

The overarching goals of HELP are to maintain physical and cognitive function throughout hospitalization; maximize independence at discharge; assist with the transition from hospital to home; and, prevent unplanned readmission. The program provides skilled interdisciplinary staff and trained volunteers to implement intervention protocols targeted toward six evidence-based delirium risk factors, which include orientation, therapeutic activities, early mobilization, vision and hearing optimization, oral volume repletion, and sleep enhancement. All patients are screened for eligibility, and interventions are assigned according to which risk factors are present. Once assigned, adherence with interventions is tracked daily, and quality assurance measures are incorporated at each step of the program.

The HELP program has been documented to be effective for prevention of delirium, ${ }^{1,3-6}$ cognitive and functional decline ${ }^{2}$, and hospital falls; 6,7 decreased length of hospital stay, $3,4,6$ institutionalization and sitter usage. ${ }^{6}$ Additionally, the program has been shown to be cost- effective, saving hospital costs of between $\$ 1165-\$ 1453$ per person per hospitalization; 4,8 decreasing long-term care nursing home costs of $\$ 13,239$ per personyear; ${ }^{9}$ and saving $\$ 149,848$ per year in sitter costs (All costs adjusted for inflation, 2013 USD). ${ }^{6}$ HELP represents one of the first multicomponent delirium intervention programs; since its creation, many intervention programs have been developed based on the principles and procedures of the HELP model. 
The National Institute for Health and Care Excellence (NICE) was originally established in 1999 to reduce variation in the availability and quality of health care delivered by the National Health Service in the United Kingdom. In 2005, the mission was expanded to include the development of public health guidance to help prevent illness and promote healthier lifestyles. Part of the mission included the development of clinical guidelines based on best available evidence to recommend appropriate treatment and care of people with specific diseases and conditions. The guidelines are developed by multidisciplinary teams using standard NICE methodology including rigorous search for evidence based practice interventions, and critique by content experts, patients, and caregivers..$^{10}$ As of May, 2013, 160 guidelines have been developed and disseminated with another 65 in development. The NICE guidelines have received much attention by both clinical and lay audiences.

In July 2010, NICE developed Clinical Guideline 103, Delirium: Diagnosis, Prevention and Management, which included 10 recommendations for delirium prevention, derived based on their systematic review of the literature and evidence-based guideline process. ${ }^{11,12}$ The NICE recommendations for prevention of delirium include assessment and treatment of the following clinical factors: cognitive impairment or disorientation, dehydration or constipation, hypoxia, immobility or limited mobility, infection, multiple medications, pain, poor nutrition, sensory impairment, and sleep disturbance. Notably, HELP-related studies were used as the evidence base to support many of the NICE recommendations. Recently, prospective HELP sites have asked whether the HELP model adheres to all of the NICE guidelines. While the HELP model at that time did not allow fulfillment of all NICE guidelines, HELP presented several advantages over NICE alone. In contrast to the HELP program, the NICE guidelines do not provide practical protocols for implementation of their recommendations. Moreover, while extensively evaluated for HELP, effectiveness and costeffectiveness of the NICE guidelines have not been examined.

Thus, the overall goal of the present work was to develop new intervention protocols for HELP to align with the NICE guidelines. Our goal was to operationalize the three NICE guidelines -- hypoxia, infection, and pain -- not currently included in HELP and expand the existing HELP dehydration protocol to include constipation. Our ultimate objective with this project was to allow the NICE guidelines for delirium prevention to be fully operationalized in HELP, following rigorous procedures designed to update the existing protocols.

\section{Methods}

\section{Initial Approach}

For this process, we followed the IOM's guidelines on developing trustworthy guidelines ${ }^{13}$ as closely as possible, but within the realistic constraints of a completely voluntary (unfunded) process (Table 1). We first assembled our interdisciplinary team to develop the protocols, all of whom had interest and knowledge about aging, delirium, and the HELP model. The 6 members of the NICE to HELP team included 2 geriatricians, 1 general internist, 1 advanced practice geriatric nurse, 1 social worker, and 1 HELP coordinator. Conflicts of interest were reviewed, and no team member had any significant conflicts. Throughout the process, the NICE to HELP team maintained independence and completed their work without influence by NICE, the HELP sites, or the HELP Advisory Board. 


\section{Scope of Work}

The next step was to identify the scope of work. The NICE to HELP group directly compared the NICE guideline recommendations for delirium prevention with the HELP protocols. This review demonstrated that only three clinical factors were not covered by existing HELP protocols, and one area was partially covered. Figure 1 and Table 2 provide a comparative overview and specific details regarding the corresponding interventions between NICE and HELP that formed the basis for the present work. Based on this process, the NICE to HELP team opted to operationalize three NICE guidelines -- hypoxia, infection, and pain -- not currently included in HELP and to expand the existing HELP dehydration protocol to include constipation as a targeted area. Because infection prevention is an expansive area, the group, in consultation with clinical experts, decided to narrow the focus to 3 areas of general relevance to the HELP program: hand hygiene, prevention of aspiration pneumonia, and prevention of catheter association urinary tract infection (CAUTI). Pneumonia and CAUTI account for approximately 50\% of the hospital acquired infections in older persons. In addition, poor hand hygiene is a contributing factor to the spread of all infections, ${ }^{14-16}$ and is directly relevant to all HELP patients, staff, and volunteers.

\section{Literature Review}

To develop the new protocols, a comprehensive review of current literature was conducted with emphasis on identifying evidence on effective interventions (i.e., studies linking clinical interventions with outcomes) for the priority areas identified above. The goal was to identify best practices related to assessment of and interventions for each of the relevant clinical factors. We utilized key elements of the IOM's Standards for the conduct of systematic reviews (2011). ${ }^{17}$ We searched all English language publications using the PubMed and CINAHL electronic databases between January 1, 2008 and December 31, 2012. All of the searches initially used the terms "delirium" or "acute confusion". For each individual protocol, additional relevant terms were added as indicated. For the constipation protocol, additional key search terms included "constipation". The hypoxia protocol was developed by searching additional key search terms of "hypoperfusion", "hypoxemia", "hypoxia", "cerebral ischemia", "oxygen", and "oxygen delivery". For the infection prevention protocols (hand hygiene, catheter association urinary tract infection (CAUTI), and aspiration pneumonia) the additional key search terms included "infection", "catheter associated urinary tract infection" and "pneumonia". For the pain protocol, key search terms included "pain", "acute pain", and "pain protocols". In addition, we also conducted secondary searches of the citations utilized in the articles found. Eligibility criteria for inclusion of articles in the final search were: evidence-based clinical practice guidelines, systematic reviews, randomized clinical trials (RCTs), and observational studies. Exclusion criteria included: lack of relevance to the topic, non-English language, pediatric population, qualitative studies, case reports, abstracts, theses, and editorials. The abstracts of all identified articles were reviewed to determine eligibility, and full text review was completed prior to final inclusion (See Figure 2).

The grading of the evidence ${ }^{18,19}$ was conducted by one reviewer, checked and verified by a second reviewer, and discussed in a consensus conference with all 6 member of the NICE to HELP team. Disagreements were resolved through consensus. Level 1 evidence included 
systematic reviews or meta-analysis of RCTs and evidence-based clinical guidelines; Level 2 evidence included individual high quality RCTs or multiple high quality cohort studies; Level 3 evidence included individual cohort study or low quality RCT (e.g., $<80 \%$ followup, or randomization process unclear); Level 4 evidence included individual case control study, or historically controlled studies; Level 5 evidence included evidence from expert committee reports or opinions and/or clinical experience of respected authorities. Emphasis was placed on utilization of the highest levels of evidence for protocol development whenever possible.

\section{Protocol Development Process}

Each protocol followed the HELP format, which included identification of eligible patients for the protocol, the assessment procedures, the step-by-step intervention protocol, referrals or consultations recommended, staff education required, and adherence tracking. For each protocol, a complete list of relevant references on which the protocol is based is provided, along with rating the quality of the evidence ${ }^{18-20}$. In drafting the protocol, the team needed to consider issues of feasibility and acceptability of the recommendations for application in acutely ill older adults in the hospital setting. Finally, the team also needed to consider that the approaches had to be appropriate and not overly burdensome for the Elder Life Nurse Specialist (ELNS), the Elder Life Specialist (ELS), and/or trained volunteers. For instance, the nursing protocols needed to adhere to the consultative role of the ELNS, who is not the primary nurse, and thus, should make recommendations and not directly implement clinical care or enter orders. In addition, other protocols needed to observe the restrictions on the ELS or volunteer role. For protocol development, team members were assigned to specific protocols which they drafted based on the evidence.

\section{Protocol Review and Finalization Process}

For internal review, the completed draft was reviewed and edited by all other members of the team during at least 2 rounds of review over a 2 month period. All protocols were discussed as a team and any discrepancies were resolved through consensus building. As a final step, one team member (SD) did a final check and standard formatting of all the protocols. The protocols then underwent internal review by members of the HELP Advisory Board and Centers of Excellence. The 6 internal reviewers included 3 geriatricians, 2 geriatric nurses, and 1 geriatric social worker.

For external review, the revised draft of the protocols was reviewed by members of key stakeholder groups, including the NICE guidelines committee on delirium, American Delirium Society, European Delirium Association, Society for Hospital Medicine, and the American Geriatrics Society. In addition, the protocols were posted on the HELP website and publicized for a 60-day period of public commentary. All input from the internal and external reviewers was reviewed by the NICE to HELP team, consensus achieved, and changes incorporated into the protocols. The finalized NICE to HELP protocols will be disseminated to active HELP sites, and posted on the HELP website. In accordance with IOM standards, regular review and updating of these protocols is planned every 3 years to coincide with the planned updates of the NICE guidelines. 


\section{Results}

A total of 2089 publications were retrieved through the comprehensive literature review process (56 for the constipation protocol, 101 for the hypoxia protocol, 1598 articles for the infection prevention protocols, and 334 for the pain management protocol). An additional 50 articles were identified through secondary sources. 1952 articles were excluded after reading the abstracts and applying our criteria. The full text of the remaining 187 articles was reviewed, and 110 met the eligibility criteria for inclusion. Figure 2 summarizes the literature search process.

The 6-member internal review panel, consisting of interdisciplinary experts from the HELP Advisory Board and Centers of Excellence provided a total of 37 substantive edits to the protocols. These included 23 additions, 9 deletions, and 5 alterations of content. The distribution of these changes were: constipation 3 changes; hypoxia 6 changes; hand hygiene 12 changes; CAUTI 6 changes, aspiration pneumonia 2 changes; and pain 8 changes. The NICE to HELP team discussed all of these changes, reached consensus, and 29/37 (78\%) were incorporated in the final protocols. Changes were not made if the information was redundant, lacked supporting evidence, or contradicted recommendations elsewhere in the protocol.

The 6 external reviewers, consisting of interdisciplinary experts representing important stakeholder groups, provided a total of 17 edits to the protocols. These included 5 additions, 1 deletion, and 11 alterations of content. The distribution of these changes was: constipation 2 changes; hypoxia 0 changes; hand hygiene 2 changes; CAUTI 2 changes, aspiration pneumonia 5 changes; and pain 6 changes. All of these changes were considered minor, and were incorporated into the final protocols with approval by the NICE to HELP team.

Table 2 provides an overview of the NICE clinical factors and recommendations, along with the parallel protocol in HELP. While some of the core protocols of the HELP model are presented on Table 2, it is important to note that the HELP model is a comprehensive program that extends beyond these protocols. The program also includes geriatric nursing interventions (e.g. delirium protocol, dementia protocol, psychoactive medications, discharge planning, optimizing length of stay, and other relevant areas), interdisciplinary interventions (e.g. geriatrician consultation, community linkages, telephone follow-up, interdisciplinary rounds, and interdisciplinary consultation), as well as patient, family and staff education programs.

Table 3 provides a summary of information on the new NICE to HELP protocols, including the eligible patients, staff implementing the protocol, assessments required, and associated interventions. The protocols themselves also provide staff education recommendations, educational materials, and recommendations for tracking adherence to ensure effectiveness. Finally, quality-rated reference listings are provided for each protocol, which include systematic reviews and relevant clinical guidelines where available. 


\section{Discussion}

The systematic approach undertaken in this project has allowed full operationalization of the NICE guidelines for delirium prevention in the HELP model of care. The NICE to HELP program will facilitate full implementation of the NICE recommendations for delirium prevention, and assures consistency between the NICE recommendations and HELP protocols. Incorporating state-of-the-art evidence from systematic review of the literature, we developed three new HELP protocols addressing hypoxia, infection control, and pain management. In addition, we expanded the dehydration protocol to include constipation. The NICE guidelines recommend interventions but lack specific details or approaches, and may not provide the information required by clinicians to fully implement the recommendations in the clinical setting. Advantages of the HELP model include the provision of straightforward protocols to help guide clinical care for healthcare workers at the bedside. Thus, the NICE to HELP protocols address an important limitation of NICE guidelines by providing information to facilitate implementation and enhance consistency in their application across settings. These protocols will now be incorporated into the HELP materials.

The majority (70\%) of the NICE recommendations were previously included as core HELP interventions. Notably, some of these recommendations were included in existing HELP protocols (e.g., medication review), such as nursing protocols, but were not separately addressed on their own. Further, the delirium risk factors of constipation, hypoxia, infection, and pain were targeted in Marcantonio's proactive geriatric consultation model. ${ }^{21}$ The new protocols were all developed using state-of-the-art methods, including systematic literature reviews of best practices and current clinical recommendations, expert review, and multiple stages of iterative revision and refinement.

This project has several strengths and fills a much needed gap. First, the NICE to HELP model updates the previously developed HELP protocols that have proven clinical and costeffectiveness. These HELP protocols have been widely used in acute care hospitals, rehabilitation facilities, and nursing homes. Secondly, the newly developed HELP protocols provide conceptual consistency between international standards relating to the identification of delirium risk factors and development of preventive interventions through the NICE clinical guidelines. IOM recommendations for trustworthy guidelines ${ }^{13}$ and systematic reviews ${ }^{17}$ were adapted and followed. The protocol development process included rigorous literature review, internal peer review, and external review by interdisciplinary stakeholders. These new protocols will be of value to the clinical sites adopting and implementing the HELP program and will provide consistency to those wishing to also utilize the NICE guidelines.

Several limitations of this project deserve comment. First, while addition of these protocols may increase the effectiveness of HELP for delirium prevention, increased costs may be required for the staff time to implement these new protocols. Thus, it is not anticipated that all existing HELP sites will be able to apply these protocols, given their existing staffing limitations; however, we hope that new sites may consider adding these protocols. Moreover, some of these protocols will not be necessary at all hospitals, where such 
practices are already incorporated as part of routine nursing care. Our external expert panel indicated that many of their hospitals already had existing protocols in these areas. Some of the evidence relating to the development of the new delirium prevention protocols was limited. For example, the search using the terms "constipation" and "delirium" yielded 56 articles but none met our inclusion criteria after reviewing the full text articles. In addition, controlled clinical trial evidence was lacking in many areas. For this reason, we used evidence based practices developed for the care of older patients in general, rather than specific to delirium for our NICE to HELP protocols. We made the assumption that that the interventions developed for older patients more generally will be applicable to older patients at high risk for development of delirium. Finally, the utility and cost-effectiveness of these new protocols have yet to be established. This will be an important area for future research.

In summary, this project describes the development of three new delirium prevention protocols (hypoxia; infection; and pain) and expansion of an existing protocol (constipation/ dehydration) to augment the HELP and to fully operationalize the NICE clinical guidelines. We anticipate this project will enhance the effectiveness and improve outcomes of the HELP program in the future as it is implemented across clinical sites. While this work applied specifically to the HELP protocols, our rigorous approach may provide a helpful example for updating existing guidelines or protocols, a necessary step to maintain relevance of any clinical program.

\section{Acknowledgments}

The authors gratefully acknowledge the staff and leaders of the Hospital Elder Life Program, who work tirelessly to improve healthcare for older persons. We especially thank members of our HELP Advisory Board who helped to review the protocols including: Fred Rubin, MD, Professor of Medicine, Chairman, Dept of Medicine at UPMC Shadyside; Heidi Wierman, MD, Geriatrician, Medical Director of Geriatric Programs, Clinical Director of Hospital Elder Life Program, Maine Medical Center, Portland, ME; Susan Heisey, MSW, LCSW, ASW-G, Hospital Elder Life Program Director, Inova Health System, Falls Church, VA; Cathleen Hoffman, BSN, RN-BC, Nurse Clinician, Hospital Elder Life Program Coordinator, Wheaton-Franciscan Healthcare-St. Joseph, Milwaukee, WI; Cathy Reis, RN Clinical Nurse Specialist, Hospital Elder Life Program at Hamilton Health Sciences, McMaster University Medical Center, Hamilton, ON Canada. We also thank the following external reviewers (organizational affiliations): Dr. Malaz Boustani (American Delirium Society, American Geriatrics Society); Dr. Sophia DeRooij (European Delirium Association); Ms. Nancy Lundebjerg (American Geriatrics Society); Dr. Melissa Mattison (Society of Hospital Medicine); and Dr. John Young (NICE Guidelines on Delirium, European Delirium Association).

Funding sources: Dr. Inouye is support in part by Grant No. K07AG041835 from the National Institute on Aging (SKI) and by the Milton and Shirley F. Levy Family Chair.

\section{References}

1. Inouye SK, Bogardus ST Jr, Charpentier PA, et al. A multicomponent intervention to prevent delirium in hospitalized older patients. N Engl J Med. 1999; 340:669-676. [PubMed: 10053175]

2. Inouye SK, Bogardus ST Jr, Baker DI, et al. The Hospital Elder Life Program: A model of care to prevent cognitive and functional decline in older hospitalized patients. Hospital Elder Life Program. J Am Geriatr Soc. 2000; 48:1697-1706. [PubMed: 11129764]

3. Rubin FH, Williams JT, Lescisin DA, et al. Replicating the Hospital Elder Life Program in a community hospital and demonstrating effectiveness using quality improvement methodology. $\mathrm{J}$ Am Geriatr Soc. 2006; 54:969-974. [PubMed: 16776794]

4. Rubin FH, Neal K, Fenlon K, et al. Sustainability and scalability of the hospital elder life program at a community hospital. J Am Geriatr Soc. 2011; 59:359-365. [PubMed: 21314654] 
5. Chen CCH, Lin MT, Tien YW, et al. Modified hospital elder life program: effects on abdominal surgery patients. J Am Coll Surg. 2011; 213:245-252. [PubMed: 21641835]

6. Caplan G, Harper E. Recruitment of volunteers to improve vitality in the elderly: The REVIVE* study. Intern Med J. 2007; 37:95-100. [PubMed: 17229251]

7. Inouye SK, Brown CJ, Tinetti ME. Medicare nonpayment, hospital falls, and unintended consequences. N Engl J Med. 2009; 360:2390-2393. [PubMed: 19494213]

8. Rizzo JA, Bogardus ST Jr, Leo-Summers L, et al. Multicomponent targeted intervention to prevent delirium in hospitalized older patients: What is the economic value? Med Care. 2001; 39:740-752. [PubMed: 11458138]

9. Leslie DL, Zhang Y, Bogardus ST, et al. Consequences of preventing delirium in hospitalized older adults on nursing home costs. J Am Geriatr Soc. 2005; 53:405-409. [PubMed: 15743281]

10. National Institute for Health and Clinical Excellence. [Accessed April, 2007] The Guidelines Manual (online). May 3. 2011 Available at: www.nice.org.uk/media/FA1/59/ GuidelinesManualChapters2007.pdf

11. National Institute for Health and Clinical Excellence. [Accessed July 2010] Delirium: diagnosis, prevention and management (clinical guideline 103) (online). May 3. 2011 Available at: www.nice.org.uk/nicemedia/live/13060/49909/49909.pdf

12. National Clinical Guideline Centre. [Accessed July 2010] Delirium: Diagnosis, prevention and management (full guideline) (online). May 3. 2011 Available at: www.nice.org.uk/nicemedia/live/ 13060/49908/49908.pdf

13. Graham, R.; Mancher, M.; Wolman, DM., et al. Institute of Medicine. Clinical Practice Guidelines We Can Trust. Washington, DC: National Academies Press; 2011.

14. Christensen KLY, Holman RC, Steiner CA, et al. Infectious disease hospitalizations in the United States. Clin Infect Dis. 2009; 49:1025-1035. [PubMed: 19708796]

15. Edwards JR, Peterson KD, Andrus ML, et al. National Healthcare Safety Network (NHSN) report, data summary for 2006, issued June 2007. Am J Infect Control. 2007; 35:290-301. [PubMed: 17577475]

16. Yu VL. Guidelines for hospital-acquired pneumonia and health-care-associated pneumonia: A vulnerability, a pitfall, and a fatal flaw. Lancet Infect Dis. 2011; 11:248-252. [PubMed: 21371658]

17. Eden, J.; Levit, L.; Berg, A., et al. Institute of Medicine. Finding What Works in Health Care: Standards for Systematic Reviews. Washington, DC: The National Academies Press; 2011.

18. Oxford Centre for Evidence-Based Medicine Levels of Evidence Working Group. [Accessed 2011] The Oxford Levels of Evidence 2. Available at: http://www.cebm.net/index.aspx?o=5653

19. Sackett, DL.; Straus, SE.; Richardson, WS., et al. Evidence-based medicine: How to practice and teach EBM. 2nd. Edinburgh: Churchill Livingstone; 2000.

20. Guyatt GH, Oxman AD, Vist GE, et al. Rating quality of evidence and strength of recommendations: GRADE: An emerging consensus on rating quality of evidence and strength of recommendations. BMJ. 2008; 336:924. [PubMed: 18436948]

21. Marcantonio ER, Flacker JM, Wright RJ, et al. Reducing delirium after hip fracture: A randomized trial. J Am Geriatr Soc. 2001; 49:516-522. [PubMed: 11380742] 


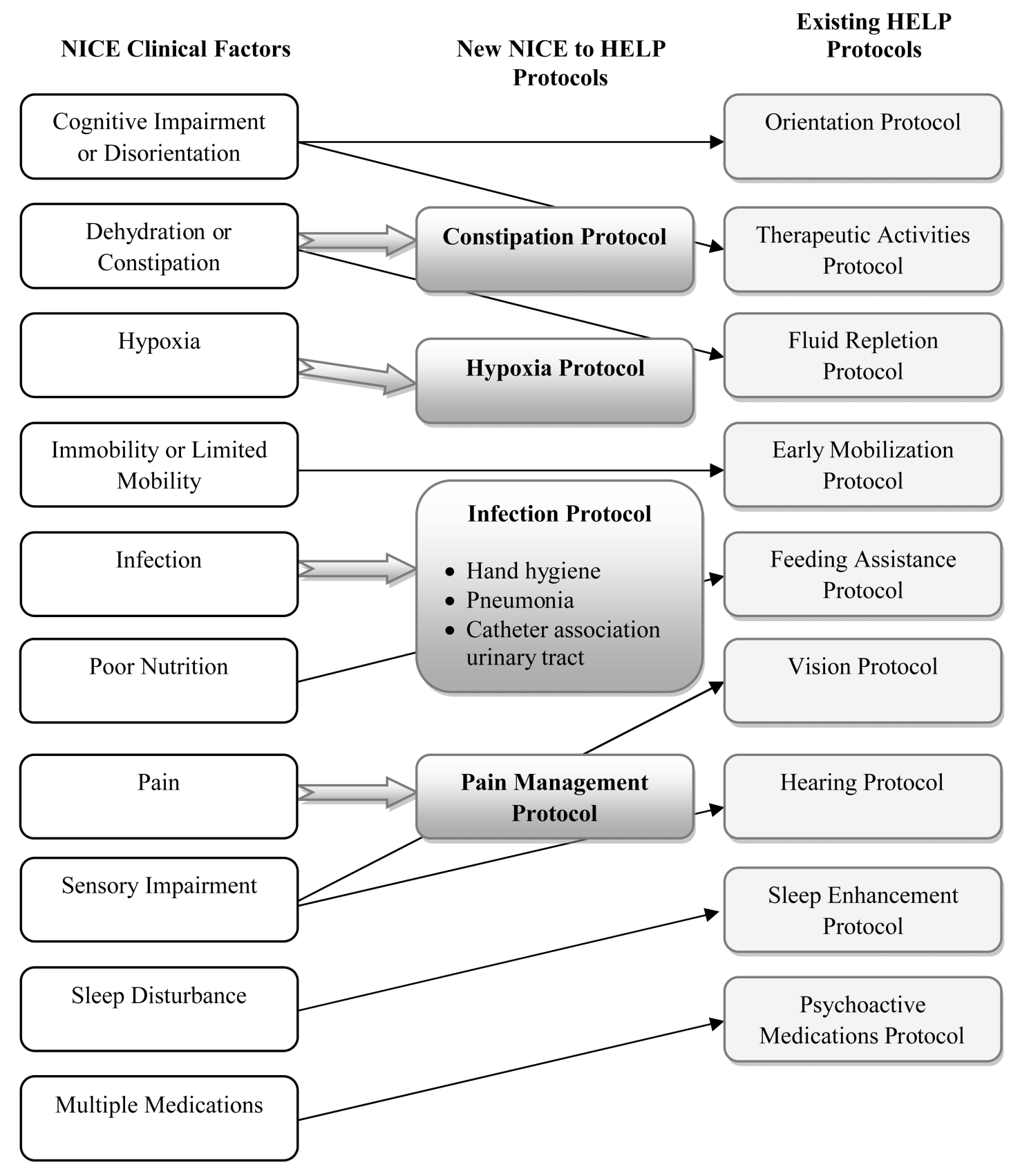

Figure 1. Relationship between NICE Guidelines and HELP Protocols*

*Note: The HELP model includes many other protocols not included in NICE. See www.Hospitalelderlifeprogram.org for full details. 
Records identified through

PubMed/CINAHL searching $(\mathrm{n}=2089)$

Constipation $(\mathrm{n}=56)$ Hypoxia $(\mathrm{n}=101)$

Infection $(\mathrm{n}=1598) \quad$ Pain $(\mathrm{n}=334)$
Additional records identified through other sources $(\mathrm{n}=50)$

Constipation $(\mathrm{n}=4)$ Hypoxia $(\mathrm{n}=11)$

Infection $(\mathrm{n}=20) \quad$ Pain $(\mathrm{n}=15)$

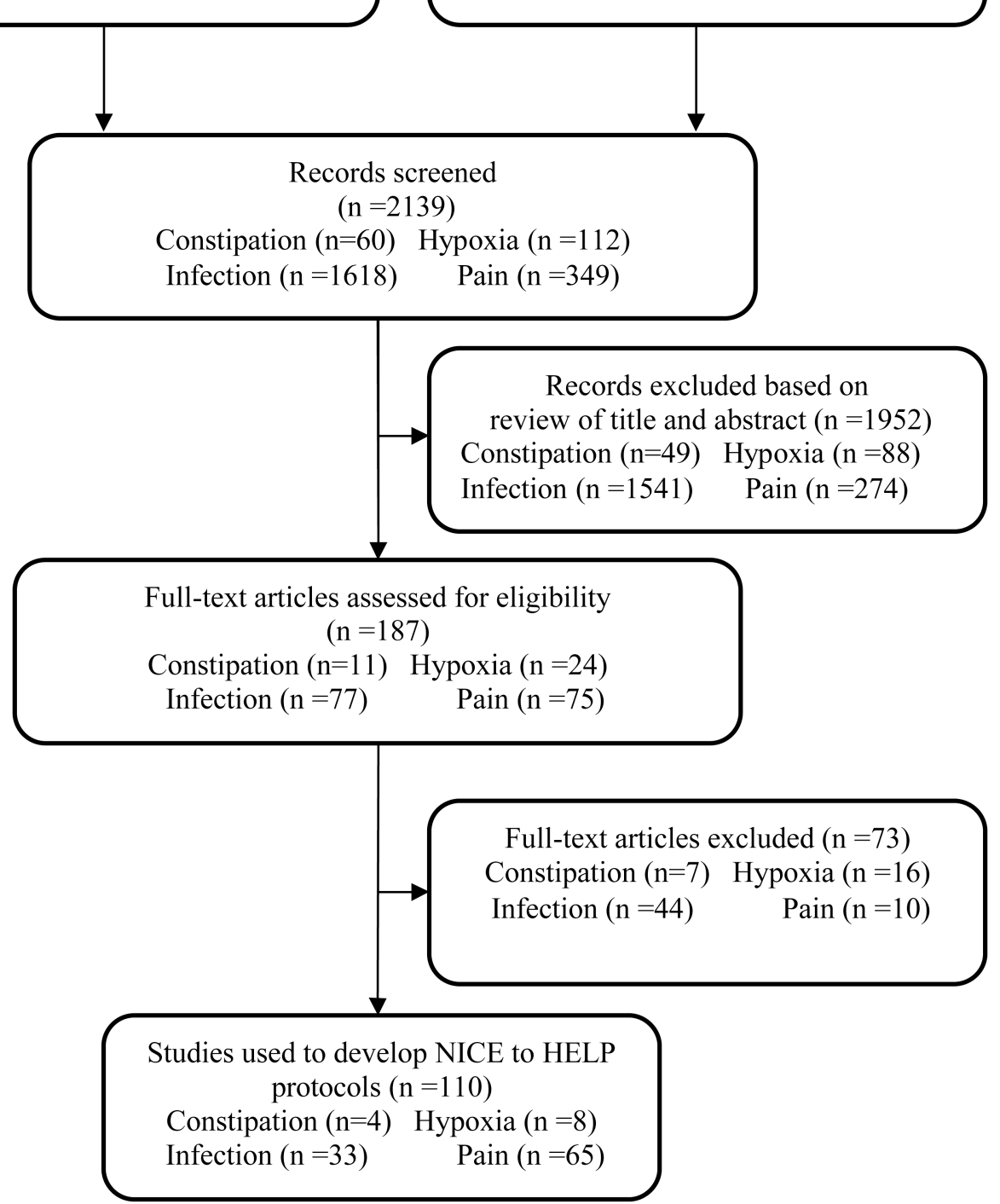

Figure 2. Flowchart of the Literature Review Process*

* See text for details 
Table 1

Implementation of Institute of Medicine (IOM) Standards for Developing Trustworthy Guidelines

\begin{tabular}{|c|c|}
\hline IOM Standard & Implementation \\
\hline $\begin{array}{l}\text { Establish a team with the required knowledge and } \\
\text { experience to conduct the review. }\end{array}$ & $\begin{array}{l}\text { The HELP Team included } 6 \text { interdisciplinary members with interest and expertise } \\
\text { in aging, delirium, and HELP. }\end{array}$ \\
\hline $\begin{array}{l}\text { Assure no significant conflict of interest (COI) relevant to } \\
\text { the work by the team members. }\end{array}$ & $\begin{array}{l}\text { COIs disclosed. No team member identified a significant conflict of interest. } \\
\text { Voluntary project, unfunded. }\end{array}$ \\
\hline $\begin{array}{l}\text { Maintain transparency, and protect the independence of the } \\
\text { team to make decisions as the process evolves. }\end{array}$ & $\begin{array}{l}\text { Team members independently carried out the review and protocol development } \\
\text { process. Team maintained independence from NICE, HELP sites, and HELP } \\
\text { leadership. }\end{array}$ \\
\hline Agreement on the key topics to be reviewed. & $\begin{array}{l}\text { Initial evaluation and comparison of the NICE and HELP protocols. Targeted to } \\
3 \text { new protocols and expansion of } 1 \text { other. }\end{array}$ \\
\hline Development of the protocol and procedures for review. & $\begin{array}{l}\text { Team agreed to utilize IOM standards as framework for the review with } \\
\text { systematic review and grading evidence, internal and external review. Agreed to } \\
\text { follow HELP format for protocols. }\end{array}$ \\
\hline $\begin{array}{l}\text { Systematic literature review. Provision of references and } \\
\text { supporting materials. }\end{array}$ & $\begin{array}{l}\text { Team members conducted comprehensive literature searches and retrieved } \\
\text { literature; hand searches of reference listings; grading of evidence. Use highest } \\
\text { level of evidence for protocols. }\end{array}$ \\
\hline Articulation of recommendations & $\begin{array}{l}\text { Drafting of protocols following the HELP format and conventions based on } \\
\text { systematic literature review and expert opinion. }\end{array}$ \\
\hline $\begin{array}{l}\text { Submission of the protocols for rigorous internal and } \\
\text { external review. }\end{array}$ & $\begin{array}{l}\text { Round } 1 \text { review by the primary team members with consensus development and } \\
\text { edits incorporated. Round } 2 \text { edits included review by members of the HELP } \\
\text { Advisory Board comprised of } 6 \text { interdisciplinary experts from the HELP Centers } \\
\text { of Excellence Review, consensus, and edits incorporated. }\end{array}$ \\
\hline Updating & $\begin{array}{l}\text { Regular review and updating of protocols is planned every } 3 \text { years to coincide } \\
\text { with planned updates of the NICE guidelines }\end{array}$ \\
\hline
\end{tabular}


Table 2

\section{NICE Recommendations and Corresponding HELP Protocols}

\begin{tabular}{|c|c|c|}
\hline NICE Clinical Factor & NICE Preventive Interventions & HELP Protocol \\
\hline $\begin{array}{l}\text { Cognitive Impairment or } \\
\text { Disorientation }\end{array}$ & $\begin{array}{l}\text { - Provide lighting, signs, calendars and clocks. } \\
\text { - } \text { Reorient the patient to time, place, person and } \\
\text { your role. } \\
\text { - Introduce cognitively stimulating activities } \\
\text { like reminiscence. } \\
\text { - Facilitate regular visits from family \& friends. }\end{array}$ & Orientation/Therapeutic activities protocols \\
\hline Dehydration or Constipation & $\begin{array}{l}\text { Encourage the patients to drink. Consider } \\
\text { advising use of parenteral fluids if necessary. } \\
\text { - } \quad \text { Seek advice regarding fluid balance in patients } \\
\text { with comorbidities (heart failure, renal disease) }\end{array}$ & Expansion of Fluid Repletion Protocol ${ }^{*}$ \\
\hline Hypoxia & - Assess for hypoxia and oxygen saturation. & Newly developed Hypoxia Protocol ${ }^{*}$ \\
\hline $\begin{array}{l}\text { Immobility or Limited } \\
\text { Mobility }\end{array}$ & $\begin{array}{l}\text { - Encourage early post-operative mobilization } \\
\text { and regular ambulation. Keep walking aids } \\
\text { (canes, walkers) nearby at all times. } \\
\text { - Encourage all patients to carry active, range- } \\
\text { of-motion exercises. }\end{array}$ & Early Mobilization Protocol \\
\hline Infection & $\begin{array}{l}\text { - } \quad \text { Look for and treat infection. } \\
\text { - } \quad \text { Avoid unnecessary catheterization. } \\
\text { - } \quad \text { Implement infection-control procedures. }\end{array}$ & $\begin{array}{l}\text { Newly developed HELP Infection Prevention } \\
\text { Protocols (Hand hygiene, pneumonia, } \\
\text { CAUTI) }\end{array}$ \\
\hline Multiple Medications & $\begin{array}{l}\text { Review medication for both the type and the } \\
\text { number of medications. }\end{array}$ & Psychoactive Medications Protocol \\
\hline Pain & $\begin{array}{l}\text { - Assesses for pain especially in those who have } \\
\text { communication difficulties. } \\
\text { Begin and monitor pain management in those } \\
\text { with known or suspected pain. }\end{array}$ & $\begin{array}{l}\text { Newly developed HELP } \\
\text { Pain Management Protocol }\end{array}$ \\
\hline Poor Nutrition & $\begin{array}{l}\text { - Follow general nutrition guidelines and seek } \\
\text { advice from dietician as needed. } \\
\text { - } \quad \text { Ensure proper fit of dentures. }\end{array}$ & Feeding Assistance Protocol \\
\hline Sensory Impairment & $\begin{array}{l}\text { - } \quad \text { Resolve reversible cause of the impairment. } \\
\text { Ensure working hearing and visual aids are } \\
\text { available and used by those who need them. }\end{array}$ & $\begin{array}{l}\text { Vision protocol } \\
\text { Hearing protocol }\end{array}$ \\
\hline Sleep Disturbance & $\begin{array}{l}\text { - Avoid medical/nursing procedures during } \\
\text { sleep if possible. } \\
\text { - } \quad \text { Schedule meds to avoid disturbing sleep } \\
\text { - } \quad \text { Reduce noise at night. }\end{array}$ & Sleep Enhancement Protocol \\
\hline
\end{tabular}


Table 3

Key Features of New NICE to HELP Protocols

\begin{tabular}{|c|c|c|c|c|}
\hline New Protocol & Eligible Patients & Staff & Assessment & Associated Intervention ${ }^{*}$ \\
\hline Constipation & $\begin{array}{l}\text { Patients at high risk of } \\
\text { constipation }\end{array}$ & $\begin{array}{l}\text { ELNS } \\
\text { ELS } \\
\text { Volunteers }\end{array}$ & Assess risk factors daily & $\begin{array}{ll}\text { - } & \text { Encourage fluids } \\
\text { - } & \text { Promote mobility and regular } \\
\text { toileting } \\
\text { - } & \text { Urge ingestion of fiber in the } \\
\text { diet }\end{array}$ \\
\hline Hypoxia Protocol & $\begin{array}{l}\text { Patients with signs } \\
\text { and symptoms of } \\
\text { hypoxia }\end{array}$ & ELNS & $\begin{array}{l}\text { Assess oxygen } \\
\text { saturation by pulse } \\
\text { oximetry }\end{array}$ & 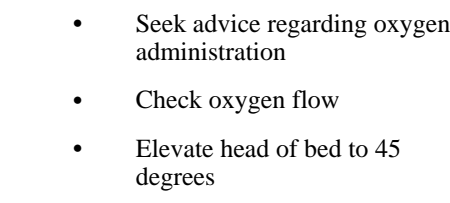 \\
\hline $\begin{array}{l}\text { Infection - Hand Hygiene } \\
\text { Protocol }\end{array}$ & All patients & $\begin{array}{l}\text { All staff } \\
\text { ELNS } \\
\text { ELS } \\
\text { Volunteers }\end{array}$ & & $\begin{array}{l}\text { - Hand washing protocol } \\
\text { - } \quad \text { Generalized infection control } \\
\text { measures }\end{array}$ \\
\hline $\begin{array}{l}\text { Infection - Aspiration } \\
\text { Prevention Protocol }\end{array}$ & $\begin{array}{l}\text { Patients at risk of } \\
\text { developing aspiration } \\
\text { pneumonia }\end{array}$ & ELNS & Assess aspiration risk & $\begin{array}{l}\text { - } \begin{array}{l}\text { Oral care regularly (every } 4 \\
\text { hours or as per hospital } \\
\text { protocol) }\end{array} \\
\text { - } \quad \begin{array}{l}\text { Head of bed to } 60 \text { degrees } \\
\text { during meals }\end{array} \\
\text { - } \quad \begin{array}{l}\text { Monitor for signs of } \\
\text { pneumonia }\end{array}\end{array}$ \\
\hline $\begin{array}{l}\text { Infection - Prevention } \\
\text { CAUTI Protocol }\end{array}$ & $\begin{array}{l}\text { Patients with } \\
\text { indwelling urinary } \\
\text { catheter }\end{array}$ & ELNS & & $\begin{array}{ll}\text { - } & \text { Sterile insertion technique } \\
\text { - } & \text { Early catheter removal }\end{array}$ \\
\hline Pain Management Protocol & $\begin{array}{l}\text { Patients with pain or } \\
\text { those with conditions } \\
\text { associated with pain }\end{array}$ & $\begin{array}{l}\text { ELNS } \\
\text { ELS } \\
\text { Volunteers }\end{array}$ & $\begin{array}{l}\text { Assess for type and level } \\
\text { of pain, observe those } \\
\text { who cannot verbalize } \\
\text { pain }\end{array}$ & 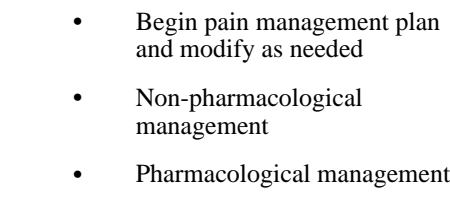 \\
\hline
\end{tabular}

